\title{
Web 2.0 in Corporate Training: New Possibilities for Implementing E-Learning within Organizations
}

\author{
doi:10.3991/ijac.v3i3.1355
}

\author{
Martínez-Aceituno, Josep Antoni, Mas García, Xavier` Guinart Orpinell, Mildred and Mendoza Jorge, Jesús \\ Universitat Oberta de Catalunya (UOC), Barcelona, Spain
}

\begin{abstract}
Web 2.0 tools offer both corporate training and online education in general the possibility of developing and applying new educational approaches. Its eminently social and participative orientation favors networking and aids the establishment of informal teaching-learning processes. This way of working and of learning can be channeled in organizations through 2.0 corporate training systems. In this paper, we set out a participative intervention method geared towards each organization defining, developing and applying its own model, while at the same time acquiring the necessary skills to consolidate it and allow it to evolve.
\end{abstract}

Index Terms-Corporate training, educational innovation, e-learning 2.0, informal learning,

\section{INTRODUCTION}

By its very social and collaborative nature, web 2.0 aids the appearance of informal peer teaching and learning processes. Nowadays, thousands of web surfers who share information select content and leave their comments on their colleagues' pages constantly and in real time. This type of dynamic contains a great training potential to which traditional e-learning systems can barely aspire. According to Bloom's Taxonomy Map for the Digital Era (see Churches, A. 2009) [1], actions such as collaborating in a wiki, posting a blog, mashing up multimedia content, actively participating in social networks or posting a videocast are activities that are associated with higher thought skills such as evaluating and creating, and which therefore favor active learning.

The aim of this paper is to present a methodology of intervention that serves to accompany the teams responsible for training in various types of organization in defining, developing and applying their own 2.0 training system. For this, after a theoretical introduction which will explicitly set out the relationships between the principal concepts around which this text revolves - corporate training, 2.0 e-learning and informal learning - we will then go on to describe a real experience carried out in the UOC Open Innovation Office as a result, as we will see, of an institutional assignment.

\section{CORPORATE TRAINING AND 2.0 E-LEARNING}

No one doubts that e-learning has been one of the contributions that has most transformed corporate learning in the last ten years ${ }^{1}$ thanks to its flexibility, its geographic non-dependence and the saving of direct and indirect costs. However, in itself, online training has not meant a significant change in relation to the effectiveness of the results of learning with regard to on-site training types. Without wishing to enter the worn-out debate on the advantages and drawbacks of on-site versus virtual, it is true to say that online training has continued to be organized as was suggested by Downes in the middle of the decade in his famous article on e-learning $2.0^{2}$ [2]- using the same templates as traditional on-site models: the course as basic training unit, participation divided into limited groups of people, the organization of roles subject to the teacher-learner layout, the communication space conceived under the traditional concept of the classroom, and learning objectives and content established beforehand by a closed curriculum. In this sense, the present LMS (Learning Management Systems) are conceived to implement e-learning models with a high degree of structuring, which hinders the possibilities of configuring creative environments while also limiting the autonomous and responsible behavior of the students (Rollett, $\mathrm{H}$. et al. 2007, 99)[3].

Their application has given rise to the development of successful e-learning models. However, the evolution undergone by the internet throughout this decade towards a more social and participative use of the web has led to the appearance of new ways of understanding education that propose more open, social and collaborative forms of learning. These types of proposal, which have in common the intensive use of 2.0 tools and the application of a high level of information abilities and skills, are part of what is known as Open Social Learning. ${ }^{3}$ Beyond the technological aspects, they also have their roots in the existence of a critical look at the old educational concepts and structures, which are seen as not very effective in providing a re-

\footnotetext{
1 According to Eurostat 2009, currently 33\% of Spanish companies use e-learning in their training programmes (See N-economía, Alert 03-062009).

2 See Downes (2005)[2]

${ }^{3}$ Under this generic name, we could find a number of initiatives, including the Facebook project by Alejandro Piscitelli, focuses such as the Edupunk concept or the Expanded Education concept and theoretical approaches such as the connectivism of George Siemens Stephen Downe. See eLearn Center (2010). El Open Social Learning y su potencial de transformación de los contextos de educación superior en España.
} 
sponse to the training challenges of the twenty-first century ${ }^{4}[4]$.

Corporate training is by no means intact from these new focuses, and in this sphere, there is an added element besides, namely the need to have both a streamlined and an ongoing training system that allows employees' immediate training needs to be met at the same speed at which they arise. A system that to be sustainable and significant for employees and organizations is capable of making the most of the internal training potential. For this, the application of training strategies and methodologies is needed that brings out the expertise and experience of the various professionals with the aim of sharing it through communicative dynamics and informal learning processes. In this sense, organizations have realized that most of what their employees learn is not through the training courses that they receive but through informal learning processes ${ }^{5}[5]$ with a high social and collaborative element, closely linked to their real context of application.

Consequently, speaking of the application of the web 2.0 in corporate training also implies referring to the management of informal learning. The 2.0 focus brings with it a number of adjectives - social, participative, open, personalized, network, non-hierarchical, etc. - that affect both the design of the educational methodologies and strategies and the ways of organizing training. In these new scenarios, it is the participants who take on the role of jointly constructing the content of the training that they receive according to their needs and expectations, as a result of not necessarily planned collaborative processes. Their activity consists of posting contributions, sharing discoveries, posing doubts, commenting on the contributions of their colleagues, selecting web contents and making sense of them in relation to the "course", etc. This entails a substantial change with regard to previous models that transforms such essential aspects of training as taking on roles (with this being more distributed), the curricular approach (with this being more open), and also the design of the training plans, with the format of the courses and the training actions being much more permeable to the day-to-day of professional performance.

These ways of relating, of communicating, of participating, of sharing and of learning, linked to the web 2.0 philosophy, fit in with the informal ways of learning of organizations. This type of learning occurs through such actions as showing, suggesting, asking for help, offering, accompanying or sharing one's own knowledge and experience in the same context in which the training need arises. This near-informal focus makes the application of 2.0 training strategies favor the emergence of initially non-planned learning, which leads to processes that are open to permanent innovation.

Despite its open nature, designing and setting up a 2.0 training system implies, above all, having a complex and systemic vision of the reality of an organization. These approaches go beyond bespoke training in which the training solutions are closed recipes formulated after a needs analysis, being applied vertically (top-down) in a finite

\footnotetext{
${ }^{4}$ See Prologue by Mayor Zaragoza in Morin (2001)[4].

${ }^{5}$ Cross, J. (2006)[5] states that, according to numerous studies, informal learning accounts for $80 \%$ of the knowledge acquired by the employees of an organisation; adding later that despite this type of learning not appearing on the route sheets of organisations, failing to recognise its existence is equivalent to leaving large sums of money on the table.
}

and controlled environment created ad hoc for the teaching of the courses ${ }^{6}$. On the contrary, the different scenarios that have the 2.0 focus as their basis move the playing field towards that reality in which real professional performance takes place, with all its complexity, connections and implications. In short, there is a shift from the formal, controlled and finite, towards the informal, open to the unplanned and continuous. The success of a training system of these characteristics requires a process of intervention based on participative methodologies, in which the organization progressively defines and applies the system, learning from it as it advances in its construction.

There are already organizations that currently run experiences for the application of 2.0 tools for their training, communicative and participative processes ${ }^{7}[6]$. Some of the best-known cases are that of Shell, which uses a Wiki system for the collaborative generation of company documentation and for sharing knowledge among its employees ${ }^{8}[7]$, and the Virt@ula 2.0 project, a training platform by the La Caixa savings bank .

\section{The DeFinition OF APPLICATION MOdELS FOR CORPORATE CONTEXTS: THE EXPERIENCE IF THE UOC OPEN INNOVATION OFFICE}

The training model linked to the use of ICT that the UOC implemented since it was created has been and is a benchmark model that a number of organizations and corporations have wanted to discover to be able to transfer it to their training programmes. For this, the University set up a bespoke training department with the aim of providing personalized advice to companies interested in applying this type of training model, adjusting it to meet their needs. The department is in touch, on the one hand, with the real needs of each corporation and, on the other, with the changes and methodological evolutions that the university experiences as the technological context offers new possibilities to the methodological scenario. Consequently, the Bespoke Training Department is a two-way drive shaft between the university and the business world both in relation to the new technological and methodological proposals applicable to corporate training and to the new demands in terms of the training needs that are generated in this sphere.

\section{A. The nature of the commission}

Organizations that have incorporated ensuring the development and growth of all their employees into their strategy are usually concerned with the refreshment and renewal of the technical knowledge linked to the functions that every member of the organization has. However, beyond this, in a technological context in constant evolution such as the present one, they are also used to ensuring the

\footnotetext{
${ }^{6}$ By this, the authors do not wish to open up any debate comparing the new focuses with other traditional approaches. We simply want to point out the essential difference between one focus and another.

${ }^{7}$ See Uhrmacher, A. (2009)[6]. This post contains an international list of companies and organisations that use social tools with different orientations and purposes. In this sense, heterogeneity is the rule, and it is hard to identify defined models with a clear training orientation. For this, an exhaustive benchmarking study needs to be conducted with this aim. There are other more extensive lists but with a marketing-oriented focus.

${ }^{8}$ See Hendrix \& Johannsen (2008)[7].

${ }^{9}$ See La Caixa (2009).
} 
refreshment and renewal of the knowledge and skills of their members with relation to the use of ICT.

For this reason, various organizations contact the UOC looking for advice or solutions to meet this type of need. To date, the UOC has been able to offer them all of the experience that it has gleaned in the design, development and implementation of online programmes and courses, offering teachers and students a virtual teaching and learning environment conceived and organized to favor communication, accompaniment and collaborative work among all the agents taking part in the training process.

However, the popularization of web 2.0 has brought with it significant changes in the behavior and habits of ICT users. Thanks to 2.0 tools, they can now take on an active role in terms of the generation and distribution of content. This is due to the fact that with little technical knowledge, it is possible to use a great variety of tools for creating content and distributing it on the net instantaneously and collaboratively ${ }^{10}[9]$. All of this has meant an evident democratization of the processes required to generate and share knowledge and to distribute content.

Taking into account these changes and the new scenarios opened in which the focus tends to move from the formal to the informal and from the finite and controlled to the open and continuous, the UOC Bespoke Training Department considered the need to conceptualize new training proposals based on the philosophy that characterizes web 2.0. To carry out the process of reflection, design and specification required to draw up an intervention model in line with this purpose, the department contacted the university's Open Innovation Office so that, in light of the new education model ${ }^{11}$ [10], it could propose the directives, guidelines and recommendations that should be taken into account when advising and guiding the companies interested in incorporating 2.0 corporate training models in their organizations.

\section{B. Analysis of the reality}

Taking as the starting point the requests made by the corporations to the Bespoke Training Department, it was decided to analyze the 2.0 tools to try and cover them. However, speaking of 2.0 tools means entering such a diffuse and apparently infinite concept that the first action that was called for was to conduct an extensive benchmarking in order to be able to demarcate the type of tools that we are discussing. This task may appear to be simple insofar as popularly a great many people coincide in replying that 2.0 tools are those that enable things to be done and shared on the net quickly, easily and for free. This definition is frequently accompanied by such examples as wiki, blog, Facebook and YouTube. At first glance, we can see that the tendency is to mix, if not confuse, types of tools (wiki, blog) with specific tools, such as Facebook (social network) and YouTube (platform for sharing and evaluating videos). We can also see that web 2.0 is identified with the possibility of any user being able to produce content (individually or collectively) of any type and share

\footnotetext{
10 See Hamburg, I. \& Hall, T. (2008, 5)[9].

11 The UOC Educational Model has evolved with the incorporation of new ways of interaction, participation and communication from web 2.0. Its aim is to foster educational innovation in the field of e-learning with the development and application of methodologies geared towards collaboration and the educational use of the latest trends in the field of ICT. See Universitat Oberta de Catalunya (2009)[10].
}

it with other users. Finally, it is worth stressing the nature of "free" that is associated with it, both in access to and use of the tools and the content that can be found in them. Although it is true to say that in some cases the free nature is limited to basic versions in terms of features, it is no less true to say that the free nature is a distinctive trait of web 2.0 that has become linked to the name "Open".

In light of the difficulty of finding a definition of web 2.0 that helps demarcate the range of tools to be taken into account in order to conduct an analysis of them, a series of characteristics was identified that we believe should be taken into account to delimit the field of observation. We took the following premises as the basis to consider a tool to be a " 2.0 tool":

a) We can access them via the internet and they may commonly be used completely or partially free of charge.

b) It is always necessary to be connected to the internet to use the tool. They are online spaces and applications (cloud computer).

c) They are social tools, for which reason they are also known by the name of social software. They allow content to be created or stored on the net and, at the same time, shared with other internet users.

Taking these premises into account, we ran a search for tools that adapted to them, and real tests were conducted with them to identify their uses, virtues and limitations. The analysis and testing resulted in a list which, far from seeking to be exhaustive, includes different categories of tools according to their most common use.

\begin{tabular}{|c|c|}
\hline Wiki & $\begin{array}{l}\text { PBwiki } \\
\text { http://pbworks.com/ } \\
\text { Wikispaces } \\
\text { http://www.wikispaces.com/ } \\
\text { PMwiki } \\
\text { http://www.pmwiki.org } \\
\text { Wikimedia } \\
\text { http://wikimedia.org }\end{array}$ \\
\hline Blog & $\begin{array}{l}\text { Wordpress } \\
\text { http://wordpres.com } \\
\text { blogger } \\
\text { http://www.blogger.com } \\
\text { Tecnorati } \\
\text { http://technorati.com } \\
\text { Google Blogsearch } \\
\text { http://blogsearch.google.es }\end{array}$ \\
\hline Microblogging & $\begin{array}{l}\text { Twitter } \\
\text { http://twitter.com }\end{array}$ \\
\hline $\begin{array}{l}\text { Social book- } \\
\text { marking }\end{array}$ & $\begin{array}{l}\text { Del.icio.us } \\
\text { http://delicious.com } \\
\text { Digg } \\
\text { http://digg.com/ } \\
\text { Diigo } \\
\text { http://www.diigo.com/ } \\
\text { Fleck } \\
\text { http://fleck.com }\end{array}$ \\
\hline Web desktops & $\begin{array}{l}\text { iGoogle } \\
\text { http://www.google.com/ig } \\
\text { Netbibes } \\
\text { http://www.netvibes.com } \\
\text { Pageflakes } \\
\text { http://www.pageflakes.com }\end{array}$ \\
\hline $\begin{array}{l}\text { Cloud comput- } \\
\text { ing \& web } \\
\text { applications }\end{array}$ & $\begin{array}{l}\text { Google Documents } \\
\text { http://docs.google.com } \\
\text { EyeOs } \\
\text { http://eyeos.info } \\
\text { Box }\end{array}$ \\
\hline
\end{tabular}




\begin{tabular}{|l|l|}
\hline & $\underline{\text { http://www.box.net }}$ \\
\hline $\begin{array}{l}\text { Social Net- } \\
\text { works }\end{array}$ & $\begin{array}{l}\text { Facebook } \\
\text { http://www.facebook.es } \\
\text { Myspace } \\
\text { http://www.myspace.com }\end{array}$ \\
$\begin{array}{l}\text { Linkedin } \\
\text { http://ww.linkedin.com } \\
\text { Ning } \\
\text { http://www.ning.com }\end{array}$ \\
\hline Calendars & $\begin{array}{l}\text { Google Calendar } \\
\text { http://www.google.com/calendar/render }\end{array}$ \\
$\begin{array}{l}\text { WhichTime } \\
\text { http://www.whichtime.com/default.php }\end{array}$ \\
\hline $\begin{array}{l}\text { Photograph } \\
\text { and multime- } \\
\text { dia managers }\end{array}$ & $\begin{array}{l}\text { Picasa } \\
\text { http://picasaweb.google.es } \\
\text { Flikr } \\
\text { http://www.flickr.com } \\
\text { Youtube } \\
\text { http://www.youtube.com }\end{array}$ \\
\hline $\begin{array}{l}\text { Note-taking } \\
\text { Google Notebook. } \\
\text { http://www.google.com/notebook } \\
\text { WebAsyst Notes } \\
\text { http://www.webasyst.net/notes }\end{array}$ \\
\hline $\begin{array}{l}\text { Mind mapping } \\
\text { bubble.us } \\
\text { http://bubbl.us/ }\end{array}$ \\
\hline $\begin{array}{l}\text { Highlighters } \\
\text { and Sticky } \\
\text { Notes }\end{array}$ & $\begin{array}{l}\text { Stickies } \\
\text { http://www.zhornsoftware.co.uk/stickies }\end{array}$ \\
\hline $\begin{array}{c}\text { To-Do lists } \\
\text { Remember the Milk } \\
\text { http://www.rememberthemilk.com/Bla-bla List } \\
\text { http://www.blablalist.com/ }\end{array}$ \\
\hline
\end{tabular}

\section{A system of analysis based on polarities}

As we can deduce from the previous sections, the design and application of a 2.0 training system in an organization is a complex problem. As García Rueda, J.J. (2008, 9) [11] points out, training in a company cannot be limited to formally planned actions but is a part, in itself, of a hyper-complex social-technical system that encompasses the whole organization, which should be tackled by applying complexity management techniques that take into account the rich environment that surrounds the learner, providing them with the resources they need to learn and evolve in it.

This means that there is not a finite number of bespoke solutions but that each case, in light of its uniqueness and complexity, is going to generate its own model. Also, this model is not going to be a stable instrument but is going to evolve following its own dynamic and reacting systemically to the changes that occur in the context. This is why it is important to have the active involvement of the protagonists through a participative methodology.

As a result of the analysis of the reality that we conducted, we came to the conclusion that the different 2.0 tools explored, taking into account the possibilities of grouping and combined uses that they permit, suggested four basic polarities with which to place the desired system, allowing us to reflect on its purpose and basic functions with regard to the whole of the organization and in terms of the participating individuals (see Fig. 1). Let us see what they are:

1. Polarity 1 . Grouping $<->$ dispersion. This defines the distribution of the spaces and tools in the system. At the grouping end are the systems organised on an environment or platform - be it a social network, an advanced LMS ${ }^{12}$ or other type of resource - created or selected to contain all the tools, spaces and functions of the system and to house its users. In this case, the participants share the same environment and carry out all their activity in it. By contrast, a totally disperse system is one that lacks centralised spaces and explicit common references. Users communicate, share knowledge and collaborate using the net openly, accessing and personalising their own resources. This would be the case of a system sustained on the PLEs (Personal Learning Environment) ${ }^{13}[12]$ of the participants.

2. Polarity 2. Private $<->$ Public. This defines the degree of openness, both of the activity of the system and of the content generated, to external users or to the net in general. This axis is especially sensitive in corporate and institutional environments as it affects questions of confidentiality and the policy of each organisation in relation to the fact of sharing knowledge with third parties. In this sense, it may be seen as a permanent risk of plagiarism or, to the contrary, as an opportunity of positioning and a possibility for establishing new alliances and collaborations. A totally private system carries out its activity impermeable to the outside. Only its members hold access and participation privileges. By contrast, a wholly public system functions permeably with regard to the net as a whole, allowing access to its main spaces and consultation of the content generated, and even offering the possibility of free subscription for external users.

3. Polarity 3. Individual<->Social. Although we always refer to social systems, this polarity defines what the starting point or centre of the activity is. When the starting point is the individual, the system is constituted on the basis of the ties and relationships that are established between the participants, with knowledge being contributed on the basis of each one's personal learning experience. On the other hand, in systems where the starting point is social, the protagonism is centred on the group. Individual actions have sense insofar as they constitute contributions to the group. Conceptually, neither of the two focuses can reach either of the extremes as both necessarily possess individual and social qualities. Perhaps an individual focus is more suitable for guaranteeing continuous learning processes beyond participation in specific actions, and a social focus is more in keeping with more defined training needs in which participation and collaboration are essential aspects.

4. Polarity 4. Formal<->Informal. This is concerned with the definition of the limits of the training activity that is carried out in the system. The formal equates to a type of highly planned and defined activity both in relation to the training objectives that they are meant to achieve and to the spatial, temporal and social delimitation of the actions. In the formal, the management of the process is established beforehand and is led hierarchically. In the case of the informal, the limit are constructed through the dynamic generated. In this case, participation can be open or semi-

12 We understand advanced LMS to be those open platforms that, as in the case of Moodle, make a firm commitment to the development and adaptation of 2.0 tools and functions for training uses.

13 See Harlem (2006) and Attwell (2007)[12]. 
open, the training objectives can be modified according to the knowledge constructed, the interests that emerge, the expectations generated or the needs detected throughout the training process.

There is no explicit management and decisions are taken between peers.

\section{Models and theoretical scenarios of application}

The polarities described above enable the profiles of different training systems to be outlined according to the positioning adopted on each one of them after the appropriate process of self-analysis and reflection. Depending on its nature and the series of problems it poses, each organization defines a different scenario. Outlining its specific profile will get its own model of application, which should be fine-tuned until it comes into operation.

With the aim of illustrating this idea, this section shows a number of examples of abstract models of application.

\section{1) Example 1. Social model:}

The starting point is the social space. The growth of individuals is the growth of the group. Individual actions are conceived to have a direct effect on the social dimension. The training experience takes place through the participative experience. It is advisable to place the emphasis on the definition of the environment as the ease of generating dynamics depends directly on this.

The environment can be created on closed social networks (Ning) and open social networks (Facebook), and to a lesser extent with other resources such as Wikis (wikispaces, Mediawiki) and shared spaces (Netvibes, Mahara, Google Sites) (see Fig. 2).

\section{2) Example 2. PLE model:}

The starting point is the PLE or Personal Learning Environment. Individual actions are aimed at the construction of the learning process itself. The social comes from the links established by the different individuals when sharing experiences, exchanging knowledge and answering requests. It is important that users have a high level of skill in terms of the use of collaborative tools and the mastery of informational skills in general. This includes having the ability to organize complexity productively, remixing the old as the basis for the new, managing public and private profiles, having a sense of reciprocity and involvement in participation, maintaining continuous connectivity and managing networks and contacts (Reig, D. 2008) [13]. Therefore, it is advisable to place special emphasis on the digital skills of the participants.

With regard to the environment, it is difficult to specify as it is made up of a complex network of links and contacts without a defined physical location, constructed on the personal collaborative tools of the participants: tweets, social bookmarks, crossover personal profiles from different social networks, posts with their respective comments, e-mail, Buzz, multimedia repositories, globalized references by Google Maps, etc. (see Fig. 3).

3) Example 3. Classical training model:

This would be the one that would be nearest a traditional training approach. In it, the participants follow what is laid down in the design of the action. Social interaction is planned and directed with explicit training aims.

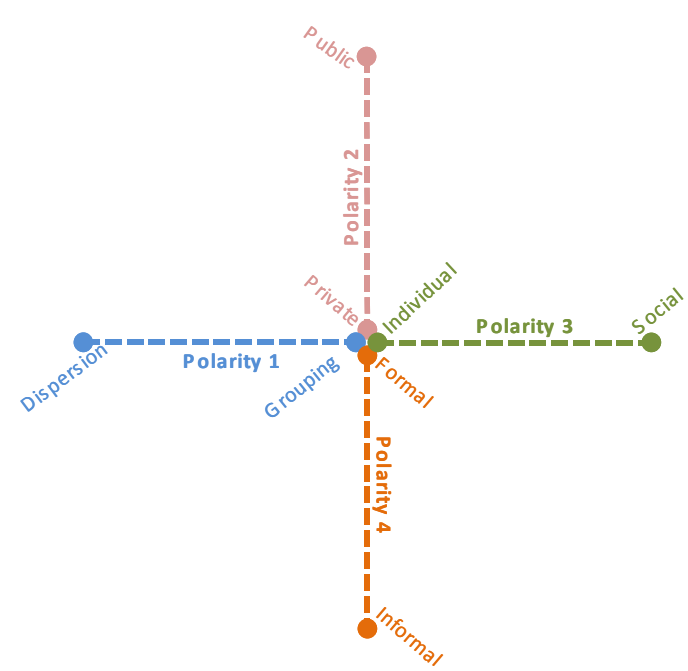

Figure 1. Basic polarities for the definition of 2.0 training systems. They guide the reflection process to define the desired system and act as coordinates to position it with regard to the whole of the organization and to the participants in terms of its purpose and basic functions.

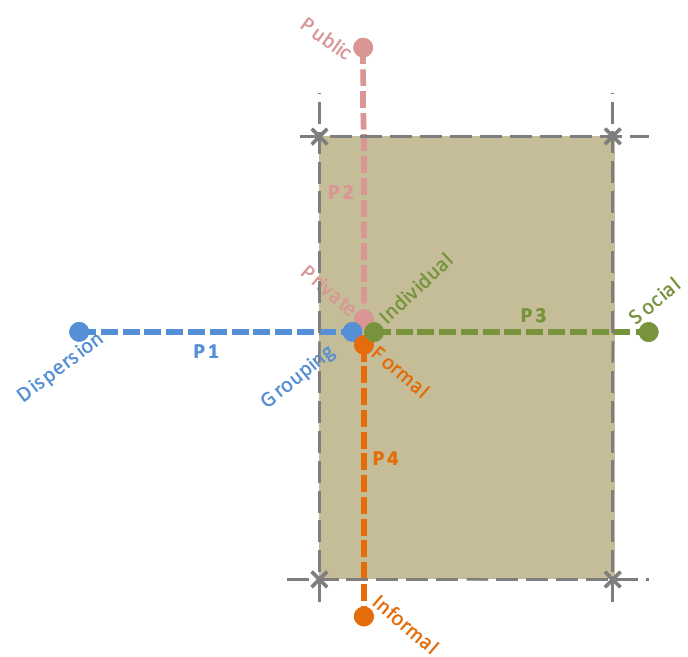

Figure 2. Profile corresponding to the example of social 2.0 training model.

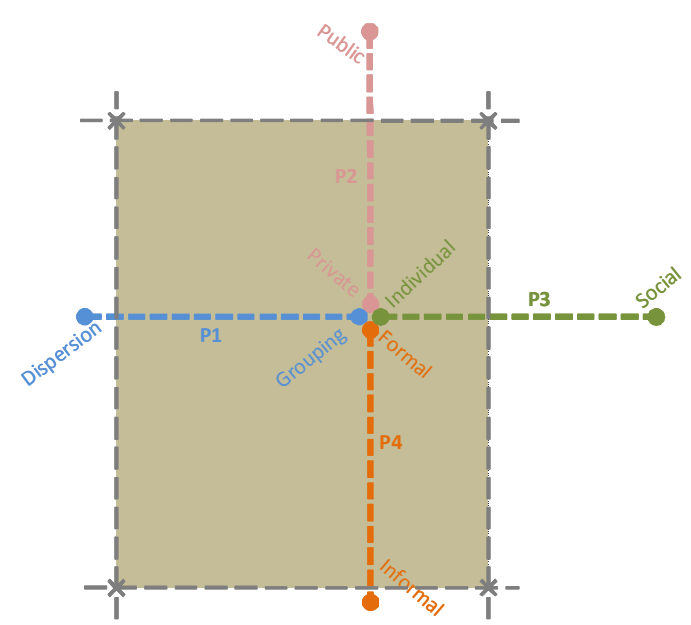

Figure 3. Profile corresponding to the example of PLE 2.0 training model. 
The environment would correspond to a conventional elearning platform such as Moodle, Dokeos, Sakay and Blackboard (see Fig. 4).

\section{E. Example 4. Corporate 2.0 model:}

This is a mixed model between the social model example (1) and the PLE model example (2) (see Fig. 2 and 3). In it, we see a clear inclination both towards the social and towards the distributed, with the public being restricted to the strict corporate or institutional sphere, and a commitment to a balance between the formal and the informal (see Fig. 5).

The main characteristic of this model is that it sets in motion two different strategies that act at different levels. On the one hand, a social environment is used to promote and carry out intentional training actions with different degrees of openness and formalization, and on the other the aim is to promote and take advantage of the informal collaborative dynamics distributed according to the PLE model to foster and disseminate the effects of the intentional actions throughout the whole organization. This way, the impact of training is not restricted to the training sphere but becomes a wave that lasts and evolves in space and time.

In this type of model, it is important to take into account the level of digital skill of the participants in the mastery of communicative and informational strategies, and an advanced and autonomous level of use of 2.0 tools. It is also important to have environments with a high degree of connectivity to all types of social tools used in PLEs, such as blogs, Twitter accounts, social bookmarks, RSS channels, etc. (see Fig. 5).

\section{F. Intervention methodology}

Having identified the binomials described above and taking into account the variety of tools and uses already identified, the intervention model that the Open Innovation Office proposed to the Bespoke Training Department revolves around five phases: preliminary interviews, configuration of the initial environment, training, configuration of the users' own environment and evaluation of the experience. We will now look at each one individually.

\section{1) Preliminary interviews}

The aim of conducting interviews with the managers of the organization is to detect the real needs and the expectations that the organization has in relation to the type of solution it hopes to find. In this case, the unique nature of the action lies in the fact that it entails a first initial level of assessment of the customer. The question is to share with them the binomials in which the end solution can be placed and to reflect with them on the pros and cons in each case. The end of the process will result in the general orientation or basic philosophy on which the type of 2.0 training will be based in each case.

\section{2) Configuration of the initial environment}

Having taken the preliminary decisions, the university carries out the first initial configuration of the environment that it will propose to the organization for it to use. This is the time to select the set of tools that should meet the previously detected needs, fulfilling the established requirements. So, for example, in each case the public or private nature that each action will have with each tool will have to be demarcated; or the type and variety of actions that each user can do in each case will be defined.

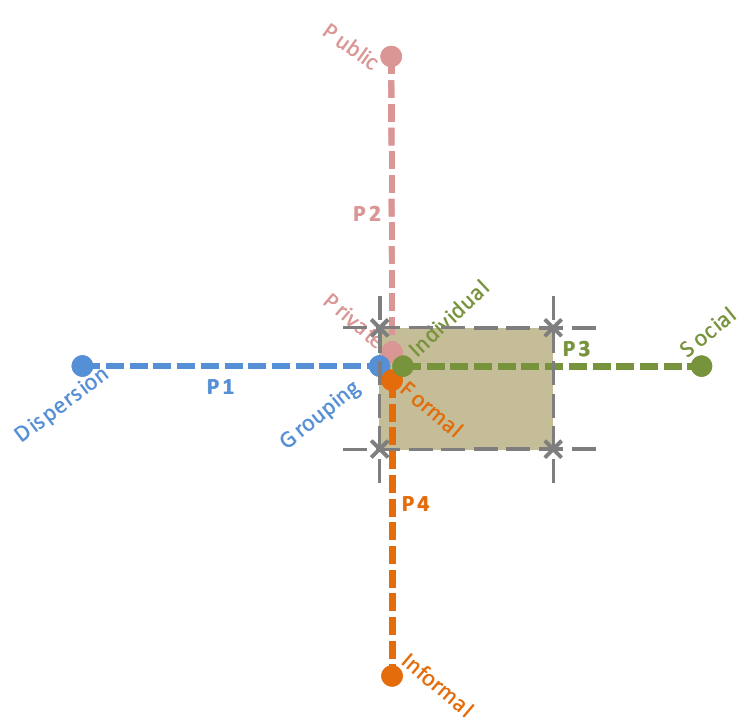

Figure 4. Profile corresponding to the example of traditional elearning training model.

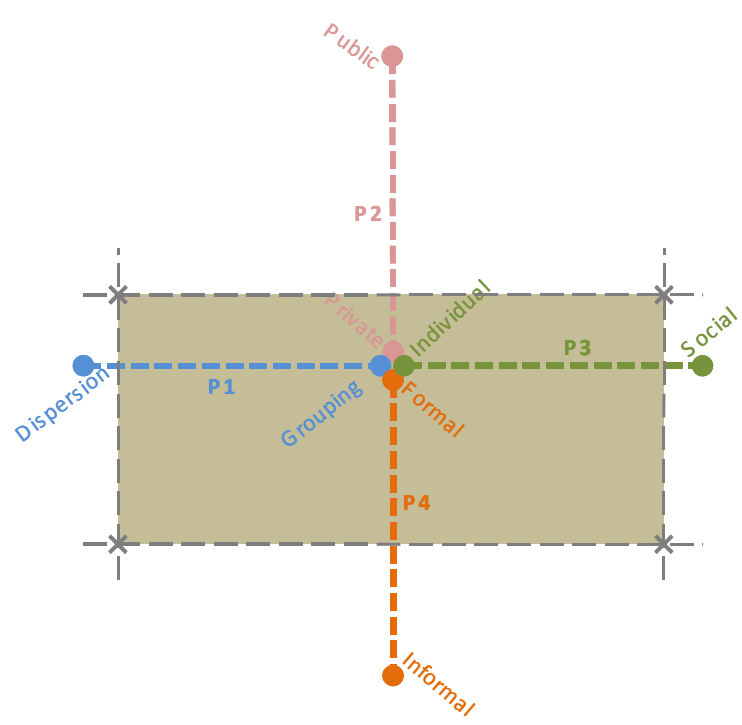

Figure 5. Profile corresponding to the example of corporate 2.0 training model.

The result of this phase will consist of a set of tools selected and configured as established in the previous phase.

\section{3) Training}

Although the proposed intervention involves constant contact with the team responsible for the roll-out of the training proposal in the organization from the first phase, it is after this third phase that its participation becomes more intense and essential. It is proposed that it follows an initial training, called "First Steps", led by the university, which has a dual aim. On the one hand, it is a question of carrying out instrumental training with regard to the tools selected with the aim that they master them and that their use does not mean a barrier to the development of a training action. On the other, the aim is for the participants to end up appropriating the use and configuration of the environment based on their own reality and objectives as an organization. The time and effort devoted to each of these dimensions is inversely proportional as the training continues (see Fig. 6). 


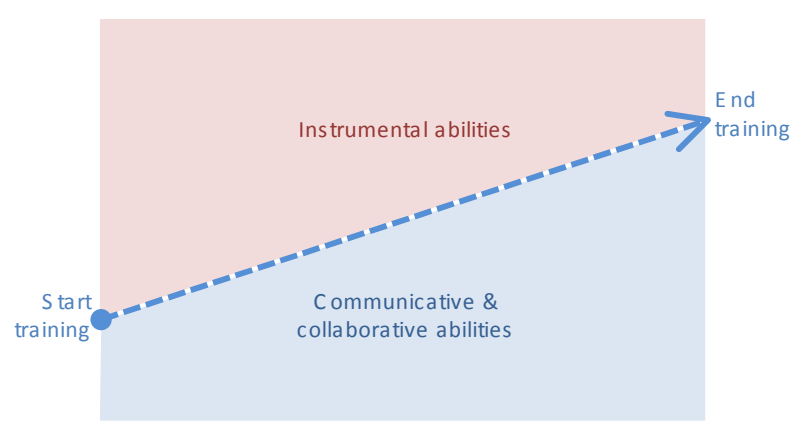

Figure 6. Progression of the type of abilities and skills worked on during the training phase.

\section{4) Configuration of the users' own environment}

In this phase, the managers of the organization construct their own solution using the tools with which they have been provided, while the university monitors this process as expert consultants acting as advisors on demand for the organization.

\section{5) Evaluation of the experience}

Finally, it is proposed that the university may participate as observer of the first real training action carried out by the organization in order to be able to conduct an evaluation of the experience, so allowing it to obtain data for the improvement of subsequent advisory proposals that are carried out with other organizations.

\section{CONCLUSIONS}

The generalized use of web 2.0 means the opening up of a sea of new methodological possibilities in the field of online training. Due to its eminently social and participative nature, these possibilities allows training in organizations to be geared towards open models that incorporate the huge potential of informal learning processes.

All of this inherently and inevitably leads to the democratization of organizations to a different extent according to the model that each one defines and applies. Consequently, it is important to overcome - or to have the ability to manage - the fear of sharing, of listening to opinions and of the establishment of more egalitarian relationships. In any event, this is an essential debate that should be present in any process of defining the model in every organization.

However, if on the one hand, a 2.0 training system tends to make the users freer, organizations also gain autonomy and flexibility in terms of the possibility of creating and generating training environments. This is due to the fact that 2.0 tools reduce the dependence on technology experts, who take on the role of advisors, and prevent the need to carry out long and costly developments. If the users are the owners of the tools, so are the members of the teams responsible for training for the conception, configuration and management of their own environments.

Due to this, the proposed intervention methodology is eminently participative and is based on the work of defining the model jointly between the advisors and the team responsible for its deployment in the organization. The aim is not solely to obtain a model in line with the wishes and needs of each organization but also the training of the team responsible for its development and implementation, in such a way that each member grows with the project. In fact, the success of this type of system depends to a large extent on the performance of the digital skills of the participants. Therefore, a good intervention should have a training dimension that ensures a good level of skills in these aspects.

\section{REFERENCES}

[1] Churches, A. (2009). Taxonomia de Bloom para la era digital. Eduteka. Online: http://www.eduteka.org/TaxonomiaBloomDigital.php

[2] Downes, S. (2005). E-learning 2.0. Elearn Magazine. Education and Technology in Perspective. Online: http://www.elearnmag.org/subpage.cfm?section=articles\&article= $\underline{29-1}$

[3] Rollett, H. et al. (2007). The web 2.0 way of learning with Technologies. International Journal of Learning Technology, Vol. 3, No. 1, pp 87-107. doi:10.1504/IJLT.2007.012368

[4] Morin, E. (2001). Los Siete saberes necesarios para la educación del futuro. Barcelona: Paidós.

[5] Cross, Jay (2006). Not Without Purpose. TD. June 2006. pp 43-45. American Society of Training and Development.

[6] Uhrmacher, A. (2009). 35+ Examples of Corporate Social Media in Action. Mashable. The social Media Guide. Online: http://mashable.com/2008/07/23/corporate-social-media

[7] Hendrix, D.; Johannsen, G. (2008). A knowledge sharing and collaboration platform. InsideKnowledge, Vol. 11, Issue 8, Posted 16 May 2008. Online:

http://www.ikmagazine.com/xq/asp/sid.0/articleid.0A6EF1DD1D6A-4CD0-94EADC872A5A708E/eTitle.Case_study_Shell_Wiki/qx/display.htm.

[8] La Caixa (2009). "la Caixa" utiliza la web 2.0 para mejorar la formación de sus empleados. Press release 20 April 2009. Online: http://prensa.lacaixa.es/view_object.html?obj=705,c,5036

[9] Hamburg, I. \& Hall, T. (2008). Informal Learning and the use of Web 2.0 within SME training strategies. eLearning Papers, No. 11. Online:

http://www.elearningpapers.eu/index.php?lng=en\&page=doc\&doc id=12791\&doclng $=7$

[10] Universitat Oberta de Catalunya (2009). El modelo educativo de la UOC. Evolución y perspectivas. Online:

http://issuu.com/innovauoc/docs/modelo-educativo-uoc Barcelona: UOC

[11] García Rueda, J.J. (2008, 9). E-learning en la empresa: ¿hay sitio para el aprendizaje informal?. Quaderns Digitals, No. 51. Online: http://www.quadernsdigitals.net/index.php?accionMenu=hemerote ca.VisualizaArticuloIU.visualiza\&articulo_id=10431

[12] Harlem, M. (2006). Personal Learning Environments. Proceedings of the Sixth International Conference on Advanced Learning Technologies (ICALT'06). Online: http://octette.cs.man.ac.uk/ mark/docs/MvH_PLEs_ICALT.pdf

[13] Reig, D. (2008). Modelo propio de competencias digitales. Online: http://www.flickr.com/photos/dreig/3689972503

\section{AUTHORS}

Josep Antoni Martínez-Aceituno is with eLearn Center, UOC, Barcelona 08035 Spain (jmartineza@uoc.edu).

Xavier Mas García, is with the eLearn Center, UOC, Barcelona 08035 Spain (xmas@uoc.edu).

Míldred Guinart Orpinell is with the Bespoke Training Department, UOC, Barcelona 08035 Spain (mguinart@uoc.edu).

Jesús Mendoza Jorge is with the Bespoke Training Department, UOC, Barcelona 08035 Spain (jmendoza@uoc.edu).

This article was modified from a presentation at the ICELW2010 Conference in New York, USA in June 2010. Submitted July 21st, 2010. Published as resubmitted by the authors July 29th, 2010. 